\title{
EXPERIENCIANDO UM MARCO CONCEITUAL PARA O CUIDADO EM ENFERMAGEM AO SER- FAMILIAR E/OU CUIDADOR E AO SER-CRIANÇA*
}

[Experiencing a conceptual landmark for the care in nursing of the familiar-being and/or care assistant and of the child-being]

\author{
Diego Schaurich** \\ Stela Maris de Mello Padoin ${ }^{* * *}$
}

RESUMO: Este artigo apresenta o marco conceitual construído a partir da prática experienciada em Enfermagem Pediátrica, buscando o aprimoramento do encontro vivido e dialogado de cuidado ao ser-familiar e/ou cuidador e ao ser-criança no mundo da vida do hospital. Para tanto, utilizou-se dos pressupostos existencial-fenomenológicos do pensamento e filosofia de Martin Buber (1977) e da Teoria de Enfermagem Humanística de Paterson e Zderad (1988). Desta forma, visa-se contribuir para o ser, saber e fazer da arte e ciência da Enfermagem ao vivenciar o genuíno e autêntico cuidado à criança e à família.

PALAVRAS-CHAVE: Teoria de Enfermagem; Família; Cuidados de enfermagem; Criança hospitalizada; Criança.

\footnotetext{
*Este artigo configura parte do Projeto de Conclusão do Curso de Graduação em Enfermagem da Universidade Federal de Santa Maria (UFSM/RS), trabalho intitulado: O Cuidado em Enfermagem

Possibilitando o Ser Mais e o Estar-Melhor do Binômio Ser-Familiar e/ou Cuidador e Ser-Criança no Mundo do Hospital.

**Enfermeiro formado pelo Curso de Enfermagem da UFSM/RS; Aluno do Programa de Educação Continuada (PEC) do Programa de PósGraduação em Educação da Universidade Federal do Rio Grande do Sul (UFRGS/RS); Membro do GEPES - Grupo de Estudos e Pesquisas em

Enfermagem e Saúde, linha de pesquisa: Processo de Cuidado e

Gestão em Saúde e Enfermagem.

***Enfermeira Docente do Departamento de Enfermagem da UFSM/RS; Mestre em Assistência em Enfermagem na Universidade Federal de Santa Catarina (UFSC/SC); Membro do GEPES, linha de pesquisa: Processo de Cuidado e Gestão em Saúde e Enfermagem; Supervisora do Projeto de Conclusão de Curso; Doutoranda da Escola de

Enfermagem Anna Nery da Universidade Federal do Rio de Janeiro (UFRJ/RJ).

***Professora Adjunta do Departamento de Enfermagem da Escola de Enfermagem da Universidade Federal do Rio Grande do Sul (UFRGS/ RS). Doutora em Filosofia da Enfermagem pela Universidade Federal de Santa Catarina (UFSC/SC).
}

\section{PRESSUPOSTOS NORTEADORES DO MARCO CONCEITUAL}

A fim de elaborar o marco conceitual para subsidiar o encontro vivido e dialogado de cuidado ao ser-familiar e/ou cuidador e ao ser-criança no mundo da vida do hospital, tanto daqueles que se encontram na Unidade de Internação Pediátrica (UIP), quanto daqueles que realizam acompanhamento ambulatorial no Serviço de Doenças Infecciosas Pediátricas do Hospital Universitário de Santa Maria (HUSM/RS), utilizouse como pressupostos teóricos e filosóficos o pensamento de Martin Buber (1977) e a Teoria de Enfermagem Humanística de Paterson e Zderad (1988).

Para melhor compreensão do pensamento destes autores, faz-se necessário pontuar alguns aspectos relevantes, conceitos e pressupostos que fundamentam a prática vivida da filosofia buberiana, bem como da Enfermagem Humanística.

\subsection{TECENDO ALGUMAS CONSIDERAÇÕES ACERCA DO PENSAMENTO E DA FILOSOFIA DE MARTIN BUBER}

A fim de subsidiar a elaboração do marco conceitual, e por representar uma das bases para elaboração da Teoria de Enfermagem Humanística de Paterson e Zderad (1988), apresenta-se a filosofia e o pensamento de Martin Buber a partir da análise da obra Eu e Tu (de tradução e introdução de Newton Aquiles Von Zuben (1977). Assim, percebe-se que a obra Eu e Tu é a 
própria experiência existencial do face-a-face se revelando, sendo para além de uma ontologia da relação; é uma reflexão sobre o EU, o TU, o ISSO, o TU-Eterno e o mundo, configurando uma verdadeira antropologia do inter-humano. O livro é dividido em três partes que se encontram interligadas: na primeira há uma apologia à relação EU-TU; na segunda há uma apresentação do relacionamento EU-ISSO; e na terceira há o diálogo silencioso da humanidade emanado do ser do homem com o TU-Eterno (Deus).

O pensamento e a filosofia de Martin Buber concentram-se na existência humana norteada pelo diálogo, pelo encontro existencial e pelo interhumano, ou seja, contém nexos com a experiência vivida. Apresenta uma proximidade interessante e uma co-responsabilidade entre a reflexão e a ação, entre práxis e logos, características que tornam seu pensamento, conhecimento e filosofia sempre atualizados (1977).

Buber (1977) parte da reflexão dialógica de que o homem é a essência da existência humana, lançando-se ao compromisso com o vivido, com a vida; no entanto, projeta seu pensamento para além, compreendendo que a essência do ser do homem se comunica com o fenômeno, com a vivência existencial de ser consigo (EU), com o outro (TU) e com o mundo. A partir do entendimento de que há uma relação entre o homem e o mundo, alcançar-se-á a condição de ser-no-mundo, em que o inter-humano, o dialógico, o vivido e o experienciado são pressupostos essenciais.

O autor supracitado percebe a relação como forma de expressão da existencialidade do serno-mundo-com-o-outro, necessitando, para ser autêntica e genuína, que o homem esteja em sua totalidade e que exista reciprocidade de presentificação. Sendo assim, o encontro firmado pela relação é fundamentalmente um fenômeno e como tal ele acontece, apresentando a essência da vivência e experiência existencial de presença no mundo da vida.

O pensamento buberiano compreende que é por meio da palavra que o ser do homem adentra a existencialidade, uma vez que ela contém o vivido, é dialógica. É a palavra que situa o homem no mundo com o outro, que o mantém no ser, que faz do ser, homem. Von Zuben (1977) acrescenta que "a palavra, como portadora do ser, é o lugar onde o ser se instaura como revelação. A palavra é princípio, fundamento da existência humana".

Percebe-se, desta maneira, que a dialogicidade presente na palavra, que fundamenta a relação ontológica do inter-humano, do encontro entre os seres, da relação de reciprocidade que se estabelece entre eles, é essência das vivências e experiências do ser como ser-no-mundo e serno-mundo-com-o-outro. No entanto, há uma ressalva a ser considerada: nossa maneira de compreender as palavras foi como que embrutecida pelo uso, tornando-nos insensíveis para o seu sentido primordial. Então em certo sentido elas nos chocam, como a verdade nos incomoda às vezes, pelo brilho de sua luz (VON ZUBEN, 1977).

E é a partir da compreensão existencial atribuída à palavra como gênese do vivido pelo ser do homem, como princípio do dialógico, que Buber (1977) apresenta o mundo como sendo duplo para o homem, mas uma dualidade complementar, não paradoxal: a atitude existencial EU-TU firmada pela relação ontológica de reciprocidade e a atitude existencial EU-ISSO, baseada no relacionamento experimental e objetivante.

Neste sentido, o filósofo refere que a palavraprincípio EU-TU somente pode ser proferida pelo ser em sua totalidade; pelo ser de presença, de relação, de reciprocidade no face-a-face existencial. Assim, a palavra-princípio EU-TU instaura um modo, uma atitude do ser do homem consigo, com o outro e com o mundo, uma vez que não existe EU sozinho, independente. Este EU torna-se presentificado, atual e atualizado em presença do TU, uma vez que é o outro que dá a possibilidade de ser e existir como EU-pessoa (SCHAURICH; PADOIN, 2003).

Sendo assim, EU-TU configura uma atitude de encontro entre dois seres que entram em relação dialógica, se reconhecessem reciprocamente e se confirmam mutuamente no tempo e espaço vividos. A partir deste encontro existencial do EU com o TU ambos tornam-se serno-mundo e ser-no-mundo-com-o-outro, pois ocorre, por meio da atitude de relação, a percepção do EU sobre o TU e vice-versa, bem como uma ação do EU sobre o TU e do TU sobre o EU.

Buber (1977) refere que o EU é uma pessoa e que o TU pode ser qualquer ser que se apresente à relação como um cachorro, um homem, uma árvore, Deus, uma nota musical. Desta maneira, acredita que o TU se oferece ao encontro - não 
sendo procurado - e o EU decide ir ao encontro, entrar em relação, firmando-se, neste sentido, uma dupla atitude existencial: a de escolher e a de ser escolhido. Assim, do EU depende a atitude de decisão ao encontro e ao TU cabe a iniciativa de encontrar e ambos tornar-se-ão EU do seu TU, entrarão em relação EU-TU no momento em que estas atitudes se presentificarem como ações atuais e atualizadas no tempo e espaço compartilhados pelos seres.

Porém, cabe ao ser do homem também outra atitude no face-a-face existencial: a atitude vinculada pela palavra-princípio EU-ISSO (BUBER, 1977). Esta palavra-princípio fundamenta um relacionamento objetivante de um EU, pessoa, com um ISSO, coisa, e jamais pode ser proferida pelo homem em sua totalidade. Neste sentido, o EU usa, experiencia, utiliza o ISSO em uma atitude de objetivação para a formação e constituição do conhecimento, do saber, da ciência.

No entanto, vale ressaltar que o ISSO é posterior ao TU, uma vez que este é primordial ao ser do homem como ser-no-mundo; é, também, a partir do mundo do ISSO que o EU tem a possibilidade de perceber e compreender autenticamente o TU e o ISSO para, a posteriori, perceber e compreender o seu EU. Sendo assim, Buber $^{(1)}$ entende o EU da palavra-princípio EUISSO como um ser egótico, ou seja, como um ser que entra em relação consigo, com seu si-mesmo e que se encontra no face-a-face existencial.

Desta forma, percebe-se que o EU da palavra-princípio EU-ISSO é um ser, uma pessoa, enquanto o ISSO é qualquer ser que se lhe defronta, como uma árvore, uma nota musical, um homem, o TU, um cachorro, mas jamais pode ser Deus - o TU-Eterno. Isso por que, todos os demais seres que fazem parte do mundo da vida do EU podem ser usados, utilizados e experienciados de forma objetiva e objetivante, configurando um ISSO, um objeto.

Entretanto, faz-se necessário resgatar, como bem frisado pelo autor, que a atitude EU-ISSO não é algo ruim ou negativo, não é inferior à atitude existencial EU-TU. Na verdade, ambas são atitudes do ser do homem no face-a-face de si mesmo, do outro e do mundo, uma vez que a primeira é essencial para a construção e elaboração do saber, do conhecimento, da ciência que rege o mundo vivido e experienciado, enquanto a segunda representa uma forma de presentificação, de encontro, de relação entre dois seres que estão abertos e disponíveis para, recíproca e mutuamente, se atualizarem existencialmente.

Para finalizar, Buber (1977) apresenta o paradoxo existente vivido pelo EU, pelo TU e pelo ISSO, uma vez que aquele torna-se EU na presença do TU, momento em que se encontram e entram em relação; contudo, basta um distanciamento, uma não reciprocidade temporal para que o EU deixe a presença na relação EUTU para adentrar ao mundo da palavra-princípio EU-ISSO, fazendo com que o TU torne-se um ISSO, um objeto de uso e utilização. No entanto, o mesmo EU de relação com o TU e de experiência com o ISSO (que anteriormente era o TU), pode tornar-se um TU e um ISSO de um outro EU, que vivencia uma outra relação EU-TU e uma outra experiência objetivante EU-ISSO.

\subsection{UM OLHAR À TEORIA DE ENFERMAGEM HUMANÍSTICA DE PATERSON E ZDERAD}

A Teoria de Enfermagem Humanística foi elaborada por Josephine Paterson e Loretta Zderad e publicada no ano de 1988 no livro Humanistic Nursing. Esta teoria teve como base 0 modelo holístico e humanístico de ser, saber e fazer em saúde, contrapondo-se ao modelo biomédico e tecnicista que lança olhares específicos e dissociados para uma das múltiplas facetas que compõem o ser humano. Esta idéia é reforçada por Meleis (1991) quando afirma que o progresso da Enfermagem como ciência humana é obstruído pelos métodos mecanicistas, deterministas e de causa e efeito.

Percebe-se que esta teoria destaca a relevância do estar-com em Enfermagem, ou seja, o ser que cuida é um ser de presença, de relação, que se encontra disposto a ajudar e está aberto ao encontro vivido e dialogado. Estes posicionamentos e preocupações incorporados pelas teóricas ao modelo de cuidado prático, vêm de encontro ao até então posto pelas ciências médicas, que privilegia o fazer-com, o conhecimento técnico-científico, os procedimentos, as normas e rotinas. 
Paterson e Zderad (1988) compreendem a Enfermagem como uma disciplina que possibilita uma transação intersubjetiva e inter-humana entre o ser que cuida e o ser que é cuidado em dado tempo e espaço vividos. Segundo as teóricas, Enfermagem é um encontro vivido e dialogado entre seres humanos que entram em relação, contendo esta "todos os potenciais humanos e limitações de cada participante único" (PATERSON; ZDERAD, 1988, P. 3).

Assim sendo, percebem a Enfermagem como arte e ciência na área da saúde, uma vez que alia o fazer-com ao estar-com no mundo da vida da pesquisa e da prática clínica. E pela condição de ser ciência e arte houve total liberdade e criatividade na construção deste modelo teórico por parte de Paterson e Zderad ${ }^{(2)}$, sendo elaborada a partir de preceitos do existencialismo e da ciência fenomenológica.

Consoante o apresentado pelas próprias teóricas, o modelo proposto a partir da prática vivida da Enfermagem Humanística não configura como uma teoria, mas como uma metateoria, ou seja, como uma teoria que possibilita a transcendência, um questionamento ontológico que forma, que permite a derivação de uma teoria. Isto é possível uma vez que configura uma estrutura aberta no tempo e espaço, permitindo que muitas vivências e experiências no mundo da Enfermagem possam ser exploradas de forma imaginativa, livre e criativa em qualquer dimensão ou situação existencial (BROUSE et al., 1989).

Neste sentido, o existencialismo, enquanto filosofia utilizada para nortear a construção do saber - do conhecimento da Enfermagem - visa desvelar e compreender o "é" das vivências e experiências inexplicáveis do ser do homem, não o seu "por quê" (PADOIN, 1999, p. 145). Assim, percebe o ser humano como único e singular em sua existencialidade, bem como um ser-derelação-com-o-outro que tem a possibilidade de escolher de forma livre e responsável como serno-mundo.

A fenomenologia é utilizada pelas teóricas no intuito de subsidiar a pesquisa em Enfermagem, delineando o método, a metodologia para o encontro vivido e dialogado de cuidado. Desta maneira, tem por objetivo lançar um olhar as coisas mesmas, ao fenômeno tal como se revela na totalidade de suas diversas dimensões a partir da compreensão do mundo da vida do homem de forma única, como ser singular, e de forma compartilhada, como ser de relação consigo, com o outro e com o mundo.

A partir destes pressupostos existencialfenomenológicos, Paterson e Zderad ${ }^{(2)}$ desenvolveram a Teoria Humanística com base no vivido e experienciado na prática clínica em Enfermagem. Faz-se essencial destacar que o modelo proposto amplia conceitos apresentados em outras teorias, como ambiente, conforto, cuidado, possibilitando vislumbrar o ser do homem de forma intuitiva, subjetiva e científica, apresentando denominações como diálogo vivido, relação e encontro.

No intuito de alcançar a compreensão acerca do EU do homem, do TU e do mundo, partem de alguns questionamentos que instigaram 0 desenvolvimento da teoria, a saber: como o ser que cuida e o ser que é cuidado interagem no mundo da vida do cuidado? Como desenvolver o conhecimento da Enfermagem como arte e ciência na área da saúde? Sendo assim, compreendem que a Enfermagem por si só representa uma resposta a um pedido velado de ajuda, e que é na busca destas respostas que o ser que cuida revela uma abertura ao encontro, à relação, ao face-aface existencial com o outro.

Neste sentido, a Teoria de Enfermagem Humanística parte de um questionamento e posterior reflexão acerca do fenômeno da vida, como possibilidade existencial do ser do homem em dado tempo e espaço vividos, a partir de uma abordagem inter-humana e intersubjetiva. Desta forma, o ser que cuida, ao revelar uma "disponibilidade-de-um-modo-de-ajuda", alcança o autêntico e genuíno encontro vivido e dialogado com o ser que é cuidado, momento em que este, também, desvela-se aberto ao outro e como um "ser-com-necessidades" (BROUSE et al., 1989, p. 209).

O relacionamento inter-humano e a intersubjetividade constituem-se elementos essenciais para o autêntico cuidado com e ao outro. Este relacionamento, na teoria de Paterson e Zderad, revela-se como uma espécie de fluxo, um entre, ou seja, um momento existencial único e singular em que o ser que cuida e o ser que é cuidado conseguem ampliar seu ângulo de visão a respeito do próprio EU, bem como do outro (TU). O relacionamento inter-humano e a intersubjetividade representam um genuíno estarcom, um modo de presença essencial com o outro, em que cada um 
torna-se mais a partir da interação no face-a-face existencial $^{(1)}$.

Assim, com a relação, o diálogo, a presença, o encontro, o chamado e resposta, estabelece-se o cuidado em Enfermagem que propicia ao ser tornar-se tudo aquilo que tem potencialidade, as escolhas livres e responsáveis e a possibilidade para estar-melhor no mundo da vida. E é a partir destas compreensões que as teóricas percebem a Enfermagem como um ato de vida; como um ato que precisa despertar a humanidade no ser do homem; como uma abertura ao processo de compreensão à existência do EU e do TU como ser-no-mundo e ser-no-mundo-com-o-outro.

No entanto, para que o encontro de cuidado aconteça faz-se necessário que o ser que cuida e o ser que é cuidado revelem a essencialidade genuína do estar-com-o-outro em seu mundo da vida; de respeitá-lo como existencialidade presentificada no encontro recíproco do face-aface; como ser que tem potencialidades em ser mais ${ }^{1}$ e limitações em não-ser. Além disso, as teóricas compreendem o ser humano a partir de suas vivências e experiências como ser de relação consigo, com o outro e com as coisas no mundo da vida, tendo liberdade para viver o autêntico cuidado de si e as decisões que permeiam esta situação.

Neste sentido, o encontro vivido e dialogado de cuidado em Enfermagem pressupõe a reciprocidade, o envolvimento, o inter-humano, o encontro entre dois ou mais seres no mundo da vida da Enfermagem, em que eles tornam-se mais do que eram antes da relação (PATERSON; ZDERAD, 1988). Assim sendo, os seres que coexistem no mundo do cuidado entram em sincronia em certo tempo e espaço compartilhados, em uma experiência existencial de ser-no-mundo e estarcom-o-outro caracterizada pela independência e interdependência.

\section{CUIDADO EM ENFERMAGEM À CRIANÇA E À FAMÍLIA}

\footnotetext{
'Ser mais é um processo dinâmico, intersubjetivo e inter-humano, alcançado quando o ser que cuida estabelece uma relação com o ser cuidado, em que ambos, após o encontro, tornam-se mais do que eram no início da interação(2). O cuidado em Enfermagem tem a capacidade de potencializar o ser mais do ser cuidado.
}

Nos tempos atuais uma série de transformações marcam as discussões em saúde, como a cronicidade de doenças - entre elas a AIDS -, a maior discussão das questões de gênero, o avanço e desenvolvimento tecnológico e a permanência conjunta dos familiares e/ou cuidadores com as crianças e adolescentes que vivenciam o estar no mundo da vida do hospital.

Neste sentido, é preciso que a Enfermagem, enquanto arte e ciência do cuidado, lance um olhar para além do ser que vivencia a doença, percebendo esta como uma possibilidade existencial; é necessário perceber a família que, juntamente a este ser, também experiencia o adoecer e requer cuidados.

Sendo assim, faz-se necessário compreender o significado de ser-criança em um mundo que apresenta tantas implicações e desafios à infância demonstrados pelas situações de risco e vulnerabilidade impostas pelo processo de pauperização, de baixa escolaridade, de agravos à saúde, de abuso e exploração sexual, de preconceitos e discriminações (PADOIN, 1999). $E$ é frente a estas situações existenciais que a Enfermagem precisa reorganizar-se a fim de potencializar o ser mais, as escolhas livres e responsáveis e possibilitar o estar-melhor da família em seu mundo da vida.

Osório (1996) refere que a família, atualmente, encontra-se em crise, uma vez que passa por um processo dinâmico e complexo de readaptação e reestruturação frente às situações vividas e experienciadas impostas pelo contexto histórico-social, econômico, político, cultural, demográfico e individual. No entanto, esta crise longe de significar um aspecto negativo, representa uma possibilidade para o ser do homem reencontrar, ressignificar, reposicionar e repensar o conceito de família no que tange aos valores, crenças, hábitos e costumes como ser-no-mundo.

Ao compreender a família como célula primordial da sociedade (OSORIO, 1996), faz-se necessário, mais especificamente relacionada ao ser-criança, vislumbrá-la como "o universo da criança", uma vez que "é sob sua intermediação que passa a existir como ser-no-mundo" (MOTTA, 1998). Sendo assim, a família torna-se o elo da criança no e com o mundo, sendo a primeira instituição social a reconhecê-la, protegê-la e 
cuidá-la como corporeidade presentificada no facea-face existencial pelo outro (SCHAURICH; PADOIN, 2003).

Neste sentido, pode-se perceber que o conceito de família, atualmente, pode ser compreendido como uma unidade que vai além da consangüinidade e da comunhão, abrangendo atitudes existenciais fundamentais ao estabelecimento de laços e vínculos de afeto, de responsabilidade com-o-outro, de respeito, de carinho, de lealdade, de solidariedade e amor. A conceituação de família pode ser percebida como a união do "ser-com-o-outro" (MOTTA, 1998), como o estar-com-o-outro, como o identificar-se com o outro em uma relação dinâmica e intersubjetiva entre o EU e o TU.

Assim, o ser que cuida em Enfermagem necessita lançar um outro olhar à família, ao serfamiliar e/ou cuidador e ao ser-criança quando ingressam no mundo da vida do hospital, no sentido de mostrar-se aberto ao outro e à relação, bem como disponibilizar um modo de ajuda que possibilite o encontro vivido e dialogado. Percebese que, ao vivenciar o cuidado ao binômio familiar, estar-se-á propiciando o tornar-se mais e o estarmelhor de ambos, uma vez que "é no contexto familiar que a criança, como ser aí, pode crescer e desenvolver suas possibilidades existenciais de vir-a-ser, e neste universo, sente-se protegida e segura ao enfrentar as crises evolutivas" (MOTTA, 1998).

Desta maneira, compreende-se por crises evolutivas, também, o complexo e dinâmico processo de saúde-doença, vislumbrados como possibilidades existenciais do ser do homem em dado tempo e espaços, como ser consigo, com o outro e com o mundo. A doença necessita ser percebida como condição de existência, como um modo-de-ser-no-mundo, como uma das possibilidades do ser em seu processo de viver.

O ser que cuida em Enfermagem precisa redimensionar o cuidado em meio as percepções e impressões do EU, do TU e do mundo das coisas com o intuito de vivê-lo e experienciá-lo de forma livre, autêntica e genuína. Tal questão apresenta maior relevância quando se trata da AIDS - como síndrome epidêmica atual - que provocou desarticulações e desestruturações no mundo da vida do ser do homem, ao trazer à tona assuntos tidos como tabus pela sociedade durante muitos anos, como: sexo, sexualidade, drogadição, integridade e valorização do corpo, processo de morrer e morte, entre outros.

Neste sentido, percebe-se que a infecção pelo HIV, por apresentar um viés epidemiológico caracterizado pelos processos de pauperização, interiorização, juvenilização e feminilização, revela o conceito de vulnerabilidade como um modo-deser-no-mundo, expresso por olhares que voltamse ao âmbito individual - consciência do indivíduo e a tomada de medidas preventivas; social acesso à escola, à saúde, à moradia, a meios de prevenção, entre outros; e programático existência de programas e ações preventivas ao HIV, recursos financeiros que os disponibilizam, entre outros -, conforme apresenta Ayres (AYRES, 1998).

Pode-se compreender, assim, que a epidemia da AIDS suscitou um repensar de ações, atitudes e comportamentos do homem em sociedade; instigou a reflexão acerca do conhecimento do EU, do outro (TU) e do mundo numa condição de existencialidade; propiciou reorganizar e redimensionar o encontro de cuidado em saúde no intuito de vislumbrar o ser tal como é, em sua história vivida, para além da doença.

Desta maneira, percebe-se que o cuidado à família, ao ser-familiar e/ou cuidador e ao sercriança que vivem ou convivem com o vírus da AIDS precisa levar em consideração aspectos como o preconceito, estigma e discriminação tão presentes ao contexto da epidemia; compreender que há um pedido de ajuda muitas vezes velado pela situação existencial de sentir-se culpado pela infecção (KNAUTH, 1997); ter como referencial este ser velado pela condição de estar portando um vírus que ainda não possui cura e que tem o desejo de ser mais e estar-melhor em seu mundo da vida.

Vislumbrando e compreendendo estas e outras questões que permeiam o contexto HIV/ AIDS é que o ser que cuida em Enfermagem necessita desenvolver o encontro vivido e dialogado de cuidado em que o ser-com HIV, com AIDS, ou simplesmente que convive com pessoas portadoras do vírus, tenha a possibilidade e a liberdade de escolher responsavelmente acerca do seu EU.

Assim, este ensaio visa apresentar um marco conceitual como possibilidade para o cuidado em Enfermagem ao ser-familiar e/ou cuidador e ao ser-criança que encontram-se lançados no mundo da vida vivendo ou convivendo com o HIVIAIDS, como 
também àqueles que se encontram em internação hospitalar.

\section{A CONSTRUÇÃO DO MARCO CONCEITUAL: NORTEANDO O CUIDADO EM ENFERMAGEM}

O marco conceitual é uma proposta teórica constituída de conceitos que se relacionam entre si, alicerçados por definições construídas à luz de um referencial teórico lógico e que pode fundamentar a práxis dos serviços em Enfermagem. Vale ressaltar, conforme 0 apresentado por alguns autores (BIELEMANN et al, 2002), que o marco conceitual facilita e favorece o processo de cuidado em Enfermagem, colaborando para uma prática mais autônoma e integral ao ser que vivencia a doença.

Assim sendo, o marco conceitual em questão foi construído visando propiciar um cuidado em Enfermagem que potencialize o ser mais e possibilite o estar-melhor ao ser-familiar e/ou cuidador e ao ser-criança no mundo do hospital, tanto daquelas crianças que (con)vivem com o HIV/ AIDS quanto daquelas que estão em internação hospitalar. Além de suscitar a reflexão no processo de cuidado, objetiva, ainda, despertar inquietações no ser que cuida em Enfermagem e o (re)pensar de ações e atitudes a fim de proporcionar um estarcom e fazer-com mais humano, ético e solidário.

Apresenta-se este marco conceitual no intuito de nortear o processo de cuidado em Enfermagem desenvolvido de forma individual e na forma de grupo - grupo operativo (ZIMERMAN, 2000) - e foi elaborado tendo por base um caminhar acadêmico que propiciou sua construção, pois parte do contexto prático dos seres envolvidos no estudo. Assim, serão descritos os seguintes conceitos: ser humano; ser criança; ser criança que (con)vive com o HIVIAIDS; família; ser familiar; ser cuidador; ser familiar e/ou cuidador que (con)vive com o HIVIAIDS; Enfermagem; grupo; e cuidado em Enfermagem.

Ser Humano - ser único e singular em sua existencialidade, em dado tempo e espaço vividos. É um ser consigo, um ser com o outro e um ser com o meio ambiente que o cerca, apresentando responsabilidades com o seu passado, presente e futuro. É um ser com potencialidades para tornar- se mais, com limitações em não-ser e vir-a-ser e com possibilidades de estar-melhor no mundo vivido e experienciado. É um ser de relação que necessita de um TU para tornar-se um EU no facea-face existencial.

Ser Criança - é um ser humano em processo incipiente no mundo, com possibilidades de crescimento e desenvolvimento físico, mental, emocional e afetivo. Ser vulnerável que precisa do TU - em especial do TU familiar e/ou cuidador - para a proteção de seu mundo da vida e de seu processo de construção e afirmação como EU, EU com o outro (TU) e EU com o meio ambiente. É um ser que precisa de proteção, amor, cuidado, carinho e solidariedade para a construção de seu mundo da vida, de sua história e de suas relações consigo e com o outro.

Ser Criança que (Con)Vive com o HIVIAIDS - é um ser criança que (con)vive, desde a mais tenra idade, no início de sua construção histórica como ser ontem, ser hoje e ser amanhã, com o Vírus da Imunodeficiência Humana (HIV) ou com a Síndrome da Imunodeficiência Adquirida (AIDS). Ser que convive com o preconceito, com o estigma e com atitudes discriminatórias, muitas vezes, desde sua concepção, mas que tem, por meio do cuidado de si e do cuidado do outro, a potencialidade de ser mais e a possibilidade de fazer escolhas responsáveis, de ser livre e de estarmelhor no mundo da vida.

Família - é formada por um conjunto de seres humanos unidos por laços de consangüinidade e/ ou laços de afeto e solidariedade. Grupo de indivíduos que compartilham momentos vividos, que vivenciam situações existenciais semelhantes e que experienciam o viver no mundo com o outro de forma coletiva. É uma unidade cuidadora que apresenta, como princípios, o respeito, a responsabilidade, o carinho, o afeto e o cuidado consigo e com o outro, sendo a primeira vivência e experiência de relação de um EU com um TU entre seres humanos no mundo e no face-a-face. Ser Familiar - é um ser humano com potencialidades de ser mais e possibilidades de estar-melhor e, também, com limitações em nãoser e em vir-a-ser. Ser que convive em família, apresentando com os demais membros laços de consangüinidade, carinho e afeto. É um serconsigo, um ser-no-mundo e um ser-no-mundo- 
com-o-outro com singularidade e capacidade de relação inter-humana.

Ser Cuidador - é um ser-no-mundo, um ser humano que estabelece as mais variadas formas de relação consigo, com o outro e com o meio ambiente. Para além destas características, apresenta potencialidade para ser mais e, por meio do cuidado de si e do outro, tem a possibilidade de estar-melhor no mundo da vida. Pode ser um ser familiar com elos de consangüinidade com o ser-criança ou apenas um ser cuidador que, por solidariedade e respeito ao TU, vivência o cuidado a este pequeno ser-no-mundo.

Ser Familiar e/ou Cuidador que (Con)Vive com o HIVIAIDS - é um ser humano, um ser familiar e um ser cuidador com potencialidades em tornarse mais e vir-a-ser. É um ser consigo (EU), com o outro (TU) e com o meio ambiente, capaz de entrar em relação e de trocar experiências e vivências em seu mundo da vida. No entanto, é um ser que convive com o preconceito e com a discriminação pois está lançado no mundo com o HIV e, assim sendo, precisa cuidar de si, cuidar do outro e ser cuidado por alguém para alcançar o estar-melhor em uma vida com mais qualidade, dignidade e cidadania.

Enfermagem - é uma profissão na área da saúde que envolve a arte e ciência do cuidado. Corresponde a arte pois o cuidado envolve criatividade, disposição, desejo, sentimentos e emoções de estar-com o outro; e é uma ciência pois contempla conhecimentos técnico-científicos, humanos, éticos e solidários. É uma disciplina humana que apresenta um ser precisando de ajuda e outro disposto a ajudar e que contém todas as capacidades e limitações dos seres envolvidos no mundo da vida do cuidado.

Grupo - é constituído por um conjunto de seres humanos que apresentam um interesse em comum e algumas idéias e pensamentos similares. No entanto, mesmo em uma experiência de grupo, as individualidades e singularidades de cada ser são preservadas, assim como suas possibilidades em estar-melhor, suas potencialidades em vir-aser e suas limitações em não-ser. O encontro em grupo permite a troca de experiências e vivências entre os participantes, ampliando o ângulo de visão pela interação no tempo e no espaço compartilhados.
Cuidado em Enfermagem - é um encontro vivido e dialogado entre o ser que está disposto a cuidar e o ser que precisa ser cuidado, em uma transação inter-humana e intersubjetiva. É um processo em que dois ou mais seres entram em relação, se reconhecem, se atualizam no tempo e espaço vividos, ou seja, momento existencial em que o encontro ocorre entre o ser que cuida e o ser que é cuidado. Por meio do cuidado em Enfermagem, o ser que cuida pode potencializar o seu ser mais e o ser mais do outro, bem como possibilitar o seu estar-melhor e o estar-melhor do outro no mundo da vida. $O$ encontro de cuidado é uma relação entre o EU e o TU, com trocas de experiências e vivências, em que os seres envolvidos tornam-se mais humanos pelo compartilhar de vida e que, ao final do mesmo, são mais do que eram no princípio da relação.

Os conceitos acima presentes nortearam o encontro vivido e dialogado de cuidado no mundo da vida do hospital, auxiliando na percepção e compreensão do binômio ser-familiar e/ou cuidador e ser-criança, tanto daqueles que se encontram na Unidade de Internação Pediátrica, quanto daqueles que acompanham as crianças que (con)vivem com o HIVIAIDS no Serviço de Doenças Infecciosas Pediátricas do Hospital Universitário onde o estudo foi desenvolvido.

\section{CONSIDERAÇÕES}

A Enfermagem, como arte e ciência na área da saúde, é uma disciplina humana que alia o estar-com-o-outro em sua existencialidade ao fazer-com caracterizado pelas normas e procedimentos no mundo da vida do hospital, segundo o apresentado na Teoria de Enfermagem Humanística de Paterson e Zderad (1988). Assim, tem a possibilidade de, por meio do encontro, do inter-humano, da relação, de um chamado e resposta, da intersubjetividade, do dialógico, potencializar o tornar-se mais do ser e proporcionar o seu estar-melhor como ser-no-mundo e ser-nomundo-com-o-outro.

Ao vivenciar a relação dialógica com o outro no mundo do hospital, ao estar-com o ser-familiar e/ou cuidador e o ser-criança que se encontram lançados existencialmente, vivendo ou convivendo com o vírus da AIDS, alcançou-se o autêntico e genuíno encontro de cuidado possibilitado pela relação EU-TU, pela reciprocidade estabelecida no face-a-face (1977). Sendo assim, proporcionou-se a abertura, a disponibilidade de ajuda, o 
reconhecimento das capacidades e limitações de cada ser, as escolhas livres e responsáveis, a essência da Enfermagem, ou seja, o cuidado que remete ao ser em sua singularidade e na totalidade de sua existência.

Neste sentido, este ensaio apresentou um marco conceitual elaborado para melhor vivenciar o encontro vivido e dialogado de cuidado em Enfermagem ao binômio ser-familiar e/ou cuidador e ser-criança que se encontram no mundo do hospital. Faz-se relevante destacar que esta construção conceitual apresenta nexos com a prática vivida, experienciada e compartilhada com o outro, durante o Estágio Supervisionado em Enfermagem na Unidade de Internação Pediátrica e no Serviço de Doenças Infecciosas Pediátricas de um Hospital Escola.

Desta maneira, percebe-se que a elaboração de um marco conceitual tem a possibilidade de auxiliar no cuidado desenvolvido no mundo da Enfermagem, uma vez que oportuniza ao ser que cuida vislumbrar o ser cuidado como único e singular em sua existencialidade, bem como promover o vir-a-ser e respeitar as impossibilidades de não-ser. Para além destas contribuições, a partir de uma abordagem existencial-fenomenológica ancorada no pensamento e filosofia de Martin Buber $^{(1)}$ e na Teoria de Enfermagem Humanística de Paterson e Zderad (1988), auxilia no desenvolvimento do ser, saber e fazer em Enfermagem, valorizando as características humanas, a ética e a solidariedade, apontando novas possibilidades de cuidado para um viver melhor.

Abstract: This article presents a conceptual landmark built from an experienced practice in Pediatric Nursing, searching for the improvement of the lived and dialogued meeting of care for the familiar-being and/or care assistant and for the child-being in the hospital world. Therefore, it made use of the phenomenological- existential assumptions of Martin Buber's thought and philosophy and of the Paterson and Zderad's Theory of Humanistic Nursing. Thus, it aims at the contribution for the being, knowing and making of art and Nursing science when experiencing the genuine and authentic care for the child and for the family.
Keywords: Nursing Theory; Family; Nursing care; Child hospitalized; Child.

\section{REFERÊNCIAS}

1 BUBER, M. Eu e Tu. 5. ed. São Paulo: Moraes, 1977.

2 PATERSON, J.E.; ZDERAD, L.T. Humanistic Nursing. New York: National League for Nursing, 1988.

3 VON ZUBEN, N.A. Introdução. In: BUBER, M. Eu e Tu. 5. ed. São Paulo: Moraes; 1977.

4 SCHAURICH, D.; PADOIN, S. M. M. O cuidado em enfermagem possibilitando o ser mais e o estar-melhor do binômio ser-familiar e/ou cuidador e ser-criança no mundo do hospital. [Trabalho de Conclusão de Curso de Graduação em Enfermagem]. Santa Maria (RS): Faculdade de Enfermagem da UFSM, 2003.

5 MELEIS, A. I. Theorical Nursing: development and progress. 2. ed. Philadelphia: JB Lippincott Company; 1991. p. $349-356$.

6 BROUSE, S.; LAFFREY, S. Paterson and Zderad's humanistic nursing framework. In: Fitzpatrick, J.; Whali, A. Conceptual Models of Nursing: analysis and application. Norwalk: Appleton \& Lange; 1989. p. $205-225$.

7 PADOIN, S. M. M. Em busca do estar melhor do ser-familiar e do ser-com AIDS. In: PROCHNOW, A. G.; PADOIN, S. M. M.; CARVALHO, V. L. Diabetes e AIDS: a busca do estar melhor pelo cuidado de enfermagem. Santa Maria: Pallotti; 1999.

8 ZANOLLI, M. L.; MERHY, E. E. A Pediatria social e as suas Apostas Reformistas. Cadernos de Saúde Pública. Rio de Janeiro, v. 17, n. 4, 2001.

9 OSÓRIO, L. C. Família hoje. Porto Alegre: Artes Médicas, 1996.

10 MOTTA, M. G. C. O ser doente no tríplice mundo da criança, família e hospital: uma 
descrição fenomenológica das mudanças existenciais. Florianópolis: UFSC/Centro de Ciências da Saúde; 1998.

11 AYRES, J. R. C. M. Vulnerabilidade dos Jovens ao HIVIAIDS: a escola e a construção de uma resposta social. In: SILVA, L. H. (Org). A escola cidadã no contexto da globalização. Petrópolis: Vozes, 1998. p. $413-423$.

12 KNAUTH, D. R. O vírus procurado e o vírus adquirido: a construção da identidade entre mulheres portadoras do vírus da AIDS. Estudos Feministas, v. 5, n. 2, 1997.

13 BIELEMANN, V. L. M.; LEMOS, D.O.; SOUZA, A. S. O interacionismo simbólico na elaboração do marco conceitual para cuidar o ser com câncer e sua família. Revista da Saúde, v. 6, n. 2, 2002.

14 ZIMERMAN, D. E. Fundamentos básicos das grupoterapias. 2. ed. Porto Alegre: Artes Médicas Sul, 2000.

ENDEREÇO DOS AUTORES Rua João Alfredo, 255/312 Cidade Baixa - Porto Alegre/RS CEP: $90050-230$ E-mail: eu_diegosch@hotmail.com Telefone: (51) 3211-0419 